\title{
OS CONDICIONANTES DA COMPETITIVIDADE INTERNACIONAL DA POMICULTURA NA REGIÃO DE FRAIBURGO/SC
}

\section{The conditioning factor of international competitivity of Fraiburgo, a region of pomiculture in Santa Catarina state}

\author{
Lúcia Maria Fernandes de Souza Salgado GUIMARÃES ${ }^{1}$
}

\begin{abstract}
RESUMO
Durante muito tempo a maçã foi um dos principais produtos agrícolas importados pelo país, perdendo apenas para o trigo, situação tal que começou a se alterar a partir da década de 1960, quando, no município de Fraiburgo, foi criada em 1962 a Sociedade Agrícola Fraiburgo (SAFRA). A Sociedade, inicialmente destinada a produção de uvas e vinhos, pretendeu na década de 1960 expandir a experiência no cultivo de outras frutas, dentre elas a maçã. Para isso, criou em 1963 um pomar experimental de fruticultura para estudar seu comportamento e a viabilidade econômica para o cultivo comercial. Resultados preliminares em 1968 apontaram a maçã como a fruta mais viável. E no final da década de 1960 se iniciou o plantio comercial de maçãs, plantio que não foi estimulado apenas por resultados técnicos, mas também por interesses econômicos e ligações políticas do grupo Safra e dos Frey. $\mathrm{Na}$ modernidade, pode-se compreender que fatores ambientais e sócioeconômicos colocam o Brasil em uma boa situação no ranking mundial de comércio e cultivo de maçãs. A pesquisa de campo demonstrou que condicionantes são importantes para a competitividade internacional da pomicultura na região de Fraiburgo em Santa Catarina. O estudo foi realizado com base nos trabalhos de competitividade sistêmica, que é a metodologia que leva em conta os condicionantes da competitividade em âmbito internacional.
\end{abstract}

Palavras-chave: maçã; condicionantes econômicos; Fraiburgo; competitividade.

\begin{abstract}
During a long time the apple was one of the many agricultural products the country had to import, that situation began to change in 1960 when the Sociedade Agrícola Fraiburgo (SAFRA) in Fraiburgo (Santa Catarina State) was created. At first, it was aimed at the production of grapes and wine, but then the SAFRA company expanded its experience on the cultivation to other fruits including apple. Therefore, they created in 1963 a fruit field to study the apple behavior and its economical viability, the results showed the apple was the best fruit. In the end of the 1960's, the apple plantation for commercial purpose started and that what wasn't moved only by technical results but also for political reasons. Nowadays it is clear that environmental and socio-economic elements put Brazil into a very comfortable situation on the world trade ranking of apples. Research shows that environmental conditionings for the apple plantation are very important to the competition in the international market. This research was based upon the systemic competing's studies, which is the metodology that considers the environmental conditionings for competing internationally.
\end{abstract}

Keywords: Apple; Economical conditionings; Fraiburgo; Competition. 
GUIMARÃES, L. M. F. de S. S. Os condicionantes da competitividade internacional...

\section{INTRODUÇÃO}

Registra a história que a produção de maçãs chegou ao Brasil junto com os colonizadores europeus. Consta que foi, por muito tempo, realizada em pomares domésticos, sem expressão econômica.

Até o início dos anos 60 , a região de Valinhos (SP) detinha os únicos pomares comerciais do país, mas tratava-se de frutas de baixa qualidade, pouco aceitas pelo mercado. Sendo assim, o consumo nacional de maçãs era suprido pela maçã importada da Argentina, maçã de qualidade bem superior a de Valinhos.

A escala comercial da produção de maçãs foi iniciada na década de 70 e tem aumentado em importância, pois até o presente tem sido consequência do uso de tecnologias modernas e da organização da cadeia produtiva.

Dessa forma, os produtores de maçãs brasileiras, após receberem os incentivos fiscais no início do estabelecimento da cultura, passaram a suprir o país com a fruta brasileira e a importação de maçãs foi reduzida drasticamente.

A importância desse setor para o país é, entre tantos fatores, a da geração de emprego, da substituição da importação de frutas pelo país e da geração de divisas pela exportação. Diante do exposto, a presente pesquisa justifica-se tendo em vista que no ciclo 20032004 a maçã, uma fruta temperada cultivada em território nacional, gerou aproximadamente $50 \%$ das divisas recebidas no Brasil pela exportação de fruta fresca.

De fato, a pomicultura brasileira tem conseguido atingir patamar crescente de autossuficiência, avanço esse devido à presença da tecnologia e de empresas modernas.

Sendo assim, coloca-se o problema do fato de que o Estado de Santa Catarina destaca-se como a mais importante área pomícola, com crescimento na participação nacional de produção de maçãs de $48,5 \%$, em 1980, para 52,8\%, em 1993. A superfície catarinense de cultivo aumentou de 7,1 mil para 14,0 mil hectares no mesmo intervalo de anos, tendo crescido $97,2 \%$ (5,0\% a.a.).

Por causa do cultivo da maçã em Fraiburgo, o Brasil, da quase total importação de frutas, passou à exportação de frutas, situação inimaginável quando, na década de 1960, aqueles planejadores e produtores possuíam a ideia de conseguir com sucesso maçãs e outras frutas de clima temperado em um país de clima predominantemente tropical como o Brasil.

\section{CONCEITO DE COMPETITIVIDADE SISTÊMICA}

Considerando o ambiente político-ideológico contemporâneo, observa-se que há um elevado grau de homogeneidade dos diagnósticos e propostas encaminhadas para a resolução dos problemas sociais e econômicos, o que representa uma das facetas do atual contexto de globalização da economia.

Procedendo-se à análise dos discursos sobre o desenvolvimento, é possível que possa existir muita convergência no que diz respeito aos diagnósticos e propostas também nessa área. Isto é verdade também no que diz respeito às políticas de desenvolvimento regional, que tomam como pressupostos básicos para a elaboração de diagnósticos e estratégias os conceitos de competitividade sistêmica e de desenvolvimento sustentável (DINIZ FILHO, 2004).

Nesse sentido, é importante fazer algumas considerações teóricas e metodológicas sobre o conceito de competitividade sistêmica, no intuito de melhor compreender os condicionantes da competitividade.

Deve-se considerar a crescente complexidade dos sistemas produtivos e a intensificação da concorrência capitalista, ocasionadas pelo contexto da globalização e da Terceira Revolução Industrial e Tecnológica. Com isso em mente, percebem-se pelo menos dois reflexos importantes na ciência econômica dos últimos vinte anos, ou seja:

- $\quad$ primeiro, houve o fortalecimento da ideia segundo a qual a competitividade das empresas não depende apenas de fatores microeconômicos, mas também de todo o ambiente macroeconômico, político-institucional e até cultural em que as empresas atuam.

- $\quad$ segundo, foi a elaboração de teorias que procuram demonstrar que o desenvolvimento econômico nacional é função da competitividade das empresas, no sentido de que os países que apresentam crescimento econômico mais acelerado e renda per capita elevada são aqueles que hospedam empresas altamente competitivas nos mercados em que operam, sobretudo quando se trata de mercados internacionalizados.

Assim colocado, devem ser analisadas as teorias de desenvolvimento que se utilizam no conceito de competitividade sistêmica, as quais diferem das teorias 
GUIMARÃES, L. M. F. de S. S. Os condicionantes da competitividade internacional...

de matriz neoclássica na medida em que, ao invés de buscarem construir modelos matemáticos que possam explicar o desenvolvimento econômico com base nas relações entre um pequeno número de fatores determinantes, procedem a identificação de um grupo bastante amplo de fatores que condicionam a competitividade das empresas e os classificam segundo esquemas lógicos que procuram revelar as complexas formas de interação entre esses fatores.

Segundo Porter (1993), pode-se entender que o conceito de vantagem competitiva é a fundamental concentração geográfica das indústrias dentro das nações. Assim sendo, as políticas governamentais, tanto em nível estadual quanto municipal, assumem papel importante na formação da vantagem nacional. Mas as questões subjacentes são ainda mais amplas do que o papel das nações.

Parte do ambiente é a sua localização geográfica, com tudo o que isso significa em termos de história, custos e demanda.

Fajnzylber (1992) explica que desde a reestruturação produtiva das décadas de 70 e 80 o tema da competitividade tornou-se bastante frequente no debate econômico contemporâneo. O que ocorreu foi que as transformações econômicas dos anos 80 e 90 foram paulatinamente suplantando as visões tradicionais sobre a competitividade ao ampliar os elementos constitutivos da capacidade de competir das nações, que culminaram na noção de "competitividade sistêmica".

Essa teoria permitiu que se chegasse à compreensão de que o funcionamento da economia depende de um conjunto de sinergias e externalidades, levando Fajnzylber (1992) a agregar uma nova dimensão à análise da competitividade: o seu caráter sistêmico.

Em concordância com Fajnzylber (1971), a ideia de competitividade sistêmica abrange duas vertentes teóricas bastante distintas sobre política industrial: uma que define tal política de modo restrito e se fundamenta na corrente principal da economia e outra que a define de modo abrangente e se fundamenta na teoria econômica evolucionária/neoschumpeteriana.

No primeiro caso, ocorre a intervenção do governo em setores ou indústrias específicas para corrigir falhas de mercado (economias de escala, externalidades, bens públicos, fatores dinâmicos, incerteza, informação imperfeita) e essa intervenção se justifica se os seus benefícios excederem os custos decorrentes de possíveis falhas de governo. No segundo caso, além da intervenção em setores ou indústrias específicas, contam também os efeitos industriais das políticas macroeconômicas e medidas em outras áreas, levando em conta as relações entre concorrência e ambiente econômico, estratégias das empresas e estruturas de mercado.

A competitividade sistêmica trata do sistema econômico como um todo, buscando criar um ambiente competitivo, gerando externalidades positivas e criando instituições em sentido amplo (inclusive as próprias políticas) para estimular a competição e privilegiar a dimensão setorial em função das diferentes intensidades tecnológicas e padrões de inserção internacional que caracterizam setores ou indústrias específicas.

Foi perceptível que a partir de 1977/78 as economias avançadas iniciaram a transição para um novo padrão de crescimento e, sobretudo, para uma nova trajetória tecnológica, com o desenvolvimento de novas tecnologias e sua difusão não só no interior da própria indústria como também na economia e na sociedade como um todo. Ademais, foram desenvolvidas novas técnicas gerenciais, novas formas de organização industrial e novas estratégias de mercado. Em sua essência, "a reestruturação produtiva nos países avançados constituiu uma das estratégias no sentido de recuperar ou manter o dinamismo industrial e a participação no comércio internacional". (SUZIGAN, 1989, p. 8)

Suzigan (1989) explica que desde logo suas estratégias de inserção internacional tiveram como foco a modernização competitiva do setor manufatureiro, alcançada, numa perspectiva de médio e longo prazo, através de uma política sistemática de incorporação de progresso técnico, aumento da produtividade, com elevação paralela dos níveis de vida da população, que lhes garantiram uma capacidade de participação crescente nos mercados internacionais.

A partir daí, Fajnzylber (1992) esclarece que o desafio da competitividade deixa de ser apenas um problema macroeconômico e passa a ser um desafio para todos os protagonistas sociais, sendo que seu fortalecimento depende do desenvolvimento de uma competitividade "autêntica", que envolve mudanças institucionais, na distribuição da renda (coesão social), no padrão de consumo e no acervo de conhecimento tecnológico.

Nesse sentido, os governos dos países industrializados, no âmbito da competitividade sistêmica, acabam incrementando a competitividade, levando a cabo políticas de caráter sistêmico: realizam programas de apoio aos setores de alto conteúdo tecnológico, reorganizam o sistema educativo, incentivam a pesquisa e desenvolvimento, apoiando em contrapartida a pequena e média empresa. 
GUIMARÃES, L. M. F. de S. S. Os condicionantes da competitividade internacional...

\section{CONDICIONANTES DA COMPETITIVIDADE}

Existem grandes obstáculos à competitividade como, por exemplo, segundo (ARAÚJO JR., 1982), o aumento de preços, pois este reflete maior conteúdo tecnológico e maior sofisticação da indústria nacional, juntamente com o aumento da eficiência na produção. Por outro lado, o mesmo autor cita que preços decrescentes indicam poucos incentivos ou baixos salários.

Segundo Dosi (1984), no Brasil, a qualidade dos produtos exportados muitas vezes é superior à dos destinados ao mercado interno. A tendência atual da indústria, a nível internacional, com a difusão em diversos segmentos da automação por microeletrônica, dá-se no sentido do aumento dos padrões de qualidade, como resultado e exigência deste processo. Assim, preços superiores associados a produtos com maiores níveis de qualidade poderiam indicar maior competitividade.

Dosi (1984) explica também que uma acepção relevante do termo qualidade é adequação ao mercado; produtos com níveis inferiores de qualidade (no sentido de performance) e preços também inferiores podem ser mais adequados à estrutura de renda e de consumo de determinados países, não denotando, portanto, ineficiência no parque produtivo.

De qualquer modo, a avaliação da qualidade e sua relação com a competitividade, além das divergências conceituais, exigem estudos específicos e detaIhados por produto, pois cada produto deve ser tratado separadamente, no contexto da sua região.

Dosi (1984) cita que a discrepância nos preços pode indicar apenas taxas de rentabilidade diferentes no mercado interno e externo, com um mesmo nível de custos ou de eficiência técnica na produção. A proteção ao mercado local - através de tarifas e barreiras não tarifárias às importações - pode permitir margens de lucro mais elevadas, interessando, ao mesmo tempo, ao exportador garantir uma presença no exterior que faça face às flutuações na demanda interna ou assegurar o aproveitamento de economias de escala com níveis mais altos de produção. A avaliação da competitividade potencial de indústrias neste caso exigiria determinar se a generalização da taxa de rentabilidade mais reduzida observada no comércio exterior inviabilizaria ou não essas indústrias.

Outro obstáculo à rentabilidade (PENALVER, 1983) seria a "ineficiência alocativa" que resulta dos sistemas nacionais de proteção à indústria. Taxas de rentabilidade artificialmente altas atraem recursos que deveriam ser destinados a outras indústrias; por outro lado, permitem a sobrevivência de indústrias ineficien- tes que prejudicam a competitividade das que utilizam seus produtos como insumos, propagando a ineficiência dentro do sistema.

Ademais, Penalver (1983) afirma que a associação da competitividade a preços apresenta ainda outros problemas que devem ser mencionados. Primeiramente, a instabilidade do sistema financeiro internacional, especialmente a partir do início da década de 80, torna as taxas de câmbio irreais e dificulta grandemente a avaliação da paridade real entre as diferentes moedas; o fato de serem realizadas exportações a determinados níveis de preços, expressos no padrão monetário local, não assegura a viabilidade de se concretizarem futuras exportações havendo flutuações nas taxas nominais de câmbio quer do país de origem dos bens, quer dos de destino.

De fato, autores como Dosi (1984) e Penalver (1983), associando também competitividade à eficiência produtiva, centram-se na análise das condições gerais do processo de produção. Especialmente a partir dos anos 60, começou a ganhar importância a corrente que, retomando o pensamento de Schumpeter sobre o papel estratégico do progresso técnico, privilegia a tecnologia como elemento central na configuração e evolução dos sistemas econômicos e dos fluxos internacionais de comércio. O fato é que a morfologia geral e limites dos processos econômicos são moldados de forma bastante rígida pelo universo tecnológico e, mais precisamente, pelas assimetrias tecnológicas internacionais, em termos de técnicas de produção e tecnologias de produto disponíveis. A composição dos fluxos de comércio é basicamente explicada pelo padrão de liderança/defasagem tecnológica.

Ferraz (1989), comentando a indústria brasileira, avança no sentido da avaliação mais sistematizada do desempenho tecnológico, conceituando a competitividade de uma empresa como sua capacidade de definir e implementar normas tecnológicas de funcionamento de um mercado, ou seja, de "perceber oportunidades, introduzir, difundir e se apropriar dos ganhos auferidos pelo progresso técnico". Propõe a avaliação desta capacidade a partir das seguintes "funções tecnológicas": sistema de pesquisa e desenvolvimento, de qualidade industrial, de automação de base microeletrônica (inovações incorporadas aos bens de capital) e de infraestrutura tecnológica (serviços técnicos especializados).

Além dos salários - que, como visto, são tomados como indicadores de competitividade, ora em correlação positiva ora em negativa, e como determinantes ou determinados pela competitividade - a produtividade é outra variável específica frequentemente utilizada na avaliação da competitividade. Ao contrário de salários, 
há consenso de que o aumento de produtividade em determinada indústria de um país em relação à mesma indústria nos países concorrentes está positivamente correlacionado com aumento de competitividade (NELSON, 1981).

A riqueza de um país pode ser vista como a soma das riquezas criadas pelos negócios do país. Em uma economia de mercado, as corporações geram riquezas aumentando o valor global agregado, e essas riquezas serão então distribuídas sobre a forma de maiores salários para os trabalhadores, maiores dividendos para os acionistas, maior reinvestimento para as empresas e maior receita fiscal para o Estado (KOTLER, 1993).

Contudo a vocação municipal ou regional é formada por uma série de fatores que podem ser definidos através do "Diamante" de Porter (1993), que o autor denomina como determinantes da vantagem nacional.

A análise do diamante de Porter poderá determinar qual a vocação do local, o que não garante ainda que essas empresas serão competitivas no seu mercado de atuação. Dois pontos ainda devem ser analisados: a) a forma de organização das empresas e b) o ambiente em que elas estão inseridas.

Porter (1993) identifica os determinantes da vantagem nacional e propõe o seu modelo para desenvolvimento socioeconômico:

- 1. Condições de fatores: Dizem respeito aos fatores de produção que afetam a competitividade das indústrias em função da qualidade e quantidade da oferta nacional. Engloba desde os recursos naturais e a oferta de mão de obra, passando pelas infraestruturas básicas de transportes, energia e telecomunicações, até os equipamentos de infraestrutura mais sofisticados, tais como centros de pesquisa e universidades.

- 2. Condições de demanda: Envolvem as características da demanda nacional para os produtos ou serviços de uma indústria. Até mesmo elementos culturais, como o valor simbólico atribuído a determinados bens de consumo conspícuo, afetam a competitividade das indústrias ligadas à produção desses bens, na medida em que eleva a exigência dos consumidores com relação à qualidade.
- 3. Indústrias correlatas e de apoio: A presença ou não, no país, de indústrias fornecedoras e de apoio que sejam internacionalmente competitivas, sendo que o autor define as indústrias de apoio. ${ }^{2}$

- 4. Estratégia, estrutura e rivalidade das empresas: As condições jurídico-institucionais, culturais e econômicas que definem o modo pelo qual as empresas de um país são criadas, organizadas e dirigidas, bem como a natureza da competição entre as empresas no mercado interno.

Michael Porter afirma a centralidade do "panorama nacional" na determinação da competitividade das empresas e, mediante a sistematização dos resultados de dezenas de estudos de caso sobre as indústrias de dez países bastante diferentes, chega a um sistema classificatório baseado em "quatro amplos atributos que modelam o ambiente no qual as empresas competem e que promovem (ou impedem) a criação da vantagem competitiva" (PORTER, 1993, p. 87).

A esses quatro determinantes da vantagem competitiva das nações (que atuam de forma mutuamente fortalecedora), Porter acrescenta ainda dois elementos que afetam positiva ou negativamente a competitividade das empresas de uma nação. O primeiro deles é o papel do "acaso" na história das empresas que lograram assumir a liderança competitiva internacional, visto que eventos totalmente fortuitos, tais como guerras, crises do petróleo ou rupturas tecnológicas podem beneficiar ou prejudicar fortemente as trajetórias das empresas. O segundo elemento é o papel do governo, na medida em que as políticas nacionais afetam os determinantes da vantagem competitiva das empresas.

O governo tem importante influência sobre a vantagem competitiva nacional, embora seu papel seja inevitavelmente parcial. A política governamental falhará se continuar sendo a única fonte de vantagem competitiva nacional.

As políticas bem-sucedidas funcionam nas indústrias onde os determinantes subjacentes da vantagem nacional estão presentes e onde o governo os reforça.

O governo, ao que parece, pode apressar ou au-

2 [...] aquelas em que empresas podem partilhar atividades na cadeia de valores através das indústrias (por exemplo, canais de distribuição, desenvolvimento de tecnologia) ou transferir conhecimentos protegidos pelo direito de propriedade de uma indústria para outra. Um exemplo de três indústrias correlatas é a de carros, caminhões leves e empilhadeiras (usadas para manuseio do material dentro e fora de fábricas e armazéns) (PORTER, 1993, p. 150). 
GUIMARÃES, L. M. F. de S. S. Os condicionantes da competitividade internacional...

mentar as probabilidades de obter vantagem competitiva (e vice-versa), mas falta-lhe o poder de criar a própria vantagem (PORTER, 1993, p. 148).

Nesse contexto, nota-se que o modelo teórico elaborado por Michael Porter atribui ao Estado um papel bem mais limitado na criação de condições de competi- tividade do que outros trabalhos que se dedicam a esse tema. Por esse motivo, esse trabalho estuda, a partir de suas ideias, a história da pomicultura na região de Fraiburgo, procurando identificar os fatores da produção favoráveis na região bem como procura identificar os condicionantes da competitividade da pomicultura na região em sentido mais amplo.

\section{A POMICULTURA BRASILEIRA NO MERCADO MUNDIAL}

Kovaleski (2006) indica que o Brasil, em 1970, era o maior importador de maçã do Hemisfério Sul e o quinto no ranking mundial. Foram ali iniciados os plantios de macieiras na região de Fraiburgo (Estado de Santa Catarina) e, logo depois, em Vacaria (Estado do Rio Grande do Sul). As empresas, motivadas pelos incentivos fiscais do governo, utilizaram a cultura como reflorestamento. Muitas desistiram da atividade, porém a maioria teve o firme propósito de transformar a maçã em um grande negócio e, assim, a fruticultura se expandiu e o País atingiu, após 25 anos, praticamente a autossuficiência, exportando uma parcela da produção. Há mais de uma década que o Brasil experimenta o sabor da exportação para mercados extremamente exigentes em consumo de frutas, como a Europa e os Estados Unidos, competindo com produtores tradicionais de maçã como Argentina, Chile e Nova Zelândia (KOVALESKI, 2006).

Na ótica de Gonçalves et al. (1996), a produção brasileira de maçã tem aumentado significativamente nas últimas décadas, permitindo a transformação do Brasil de importador em exportador dessa fruta. A produção nacional, que era de 14,6 mil toneladas em 1977, cresceu sistematicamente para atingir 517,5 mil toneladas em 1993, numa expansão de $3.444,5 \%$ em 17 anos, o que em média representaria a expressiva taxa de $61,5 \%$ a.a.

A mesma fonte registra também que a pomicultura brasileira, além de ter conseguido com sucesso atingir patamar crescente de autossuficiência, ensaia movimento sólido no sentido da exportação. Em 1986, quando se iniciavam as vendas externas, ocorreu a exportação de apenas 33 toneladas. Nos anos seguintes, houve crescimento nesse movimento, mas foi no triênio 1992-94 que se pode afirmar que o Brasil consolidou sua posição como exportador de maçã, com a venda em média de 29 mil toneladas/ano, o que demonstra a capacidade de gerar vantagens competitivas, superando obstáculos de ordem tecnológica, econômica e de organização empresarial,

imprescindíveis no segmento de frutas frescas.

Gonçalves et al. (1996) explica que a produção média mundial de maçã, no triênio 1999-2001, ficou em torno de 60 milhões de toneladas, sendo a grande responsável por este número significativo a China, cuja produção evoluiu de 5 para 21 milhões de toneladas, comparando-se os dois períodos.

Em proporções bem menores, a participação da produção brasileira na mundial evoluiu de 1,0\% para $1,5 \%$, ocupando o $13^{\circ}$ lugar em importância, pois a Alemanha, Itália e França, continuam a ser os grandes produtores europeus (somando cerca de 15\% da produção mundial) (GONÇALVES et al., 1996) (Tabela 1).

A pomicultura nacional encorpa e se consolida tecnologicamente na década de 90 , mas depois de um crescimento de 392\%, entre 1981 e 1991, a produção brasileira de maçã cresceu $153 \%$ entre 1991 e a média 2000/01. É importante destacar que, durante esse período, a evolução da área colhida ocorre a taxas menores (18\% entre 1991 e a média $2000-01)$, enquanto os rendimentos passam a crescer a taxas maiores $(114 \%$, no mesmo período).

A disponibilidade de maçã, por habitante/ano, em 1999 (FAO, 2006), foi de 8,2kg. Assim, como mais de $90 \%$ da produção e do consumo dessa fruta concentram-se nos países do hemisfério Norte, são estes os que apresentam as maiores disponibilidades por habitante/ano (Alemanha, Áustria, Dinamarca e Holanda dispõem de quantidades entre 4 e 6 vezes a média mundial). Com disponibilidades muito pequenas estão os países africanos.

Com 5,0kg por habitante/ano, a disponibilidade de maçã no Brasil, em 1999, situou-se em posição mediana e um pouco abaixo da média mundial. O aumento do consumo aparente per capita dos brasileiros deu-se na década de 90, quando aos ganhos de rendimento da cultura somou-se o ganho de renda dos consumidores (com a estabilização da moeda). Passou-se de 3,62kg/ 
GUIMARÃES, L. M. F. de S. S. Os condicionantes da competitividade internacional...

habitante em 1993 para 5,50kg/habitante em 1996 (valor máximo atingido) (ABPM, 2006). É importante citar também, neste contexto, que o consumo alimentar domiciliar per capita anual de maçã, no Brasil, aumentou $34 \%$ de 1987 a 1996, passando de 2,176kg para 2,907kg.

Os aumentos mais significativos ocorreram nas classes de recebimento mensal familiar até 10 salários mínimos, destacadamente na classe inferior, que aumentou em $128 \%$ seu consumo. A exemplo de outras frutas, a expansão da demanda por maçã depende de uma melhor distribuição de renda.

No que diz respeito às exportações, constata-se que as exportações mundiais de maçã saltaram de 3,8 para 5,3 milhões de toneladas (variação positiva de $37,5 \%$ ), sendo que a expansão mais significativa ocorreu nas exportações chinesas, que evoluíram em 310,0\%, aumentando sua participação no comércio mundial da fruta de $1,6 \%$ para $4,9 \%$. Os quatro países classificados como os maiores exportadores da fruta em 1989-93 mantiveram sua posição em 1999-00, a saber: França (16,0\% e 14,9\%, respectivamente), Estados Unidos (13,3\% e $12,3 \%)$, Itália $(9,0 \%$ e $10,9 \%)$ e Chile $(9,5 \%$ e $9,2 \%)$. Já na quinta colocação houve mudança importante: a Hungria caiu de $7,1 \%$ para menos de $1 \%$, enquanto a Bélgica ocupou o seu lugar, evoluindo de $4,0 \%$ para $7,3 \%$. O Brasil, assim como a China, teve grande expansão da produção de maçã no período considerado, com seu papel no comércio internacional aumentado de $0,4 \%$ para $1,2 \%$, graças ao incremento de $339,44 \%$ em suas quantidades exportadas, entre 1989-93 e 1999/00. Ao contrário, e em decorrência da atuação brasileira, a participação argentina caiu de $5,4 \%$ para $2,6 \%$.

De acordo com Gonçalves et al.(1996), no mesmo período, a relação entre exportação e produção mundiais variou indicando que a grande expansão da produção destinou-se prioritariamente aos mercados internos, destacadamente dos chineses.

Gonçalves et al.(1996) registra que as importações mundiais de maçã evoluíram de cerca de 3,9 milhões de toneladas, em 1989-93, para 4,8 milhões em 1999/00 (variação de 22,25\%). Os quatro países maiores importadores mundiais mantiveram suas colocações, embora perdessem um pouco da importância relativa: Alemanha (com variação de $18,5 \%$ do total importado em 1989-93 para 14,8\% em 1999/00), Reino Unido (de $11,7 \%$ para $9,2 \%$ ), Holanda (de $7,0 \%$ para $5,9 \%$ ) e Bélgica (de 5,7\% para 4,8\%). Neste contexto, os principais países que tiveram participação crescente nas importações da fruta foram: Espanha $(3,7 \%$ e $4,6 \%)$, Rússia (2,0\% e 3,8\%), México (1,1\% e 3,4\%) e China $(2,4 \%$ e $3,4 \%)$. O Brasil, em função do seu processo de substituição de importações, reduziu de 106.565 toneladas, em 1989-93, para 55.206 toneladas, em 1999/00, suas compras de maçã no mercado internacional, reduzindo sua participação de $2,7 \%$ para apenas $1,2 \%$ do total.

Perez, Gonçalves e Souza (1998) documentam que, durante a década de 90 , as exportações brasileiras de maçã também se diversificaram. Se em 1991 o Brasil exportou $97 \%$ dessa fruta para Holanda $(58,5 \%)$ e Reino Unido (38,5\%), restando apenas 3,0\% para outros destinos, em 2001, 35\% da quantidade exportada destinou-se a outros países.

No caso, é importante o dado de que a Holanda (54,82\% das exportações brasileiras) e Reino Unido $(10,51 \%)$ continuaram sendo os principais destinos, porém seguidos por outros compradores importantes, como Alemanha (8,05\%), Bélgica $(6,92 \%)$, Irlanda (4,99\%), Espanha (4,09\%) e mais Noruega, Portugal, Itália, França e Suécia (com participações entre 0,96\% e $2,43 \%$ ) e outros. Os Estados brasileiros responsáveis pela quase totalidade do volume exportado foram Santa Catarina e Rio Grande do Sul (GONÇALVES et al., 1996).

No sentido histórico, o grande fornecedor de maçã estrangeira para o mercado brasileiro tem sido a Argentina, pois em 2001, 71,78\% das quantidades importadas pelo Brasil se originaram nesse país, sendo seguida pelo Chile, com 25,30\%, França, com 2,23\% e outros países, com participação residual. No auge do impacto do Plano Real sobre a renda dos consumidores brasileiros, as importações de maçã foram maiores e mais diversificadas, buscando maior quantidade e variedade de oferta no mercado (PEREZ; GONÇALVES; SOUZA, 1998).

De fato, a análise revela que o Brasil, no que diz respeito ao comércio em geral da importação e exportação da maçã não é insignificante, podendo, contudo, haver incremento nas estatísticas. 
GUIMARÃES, L. M. F. de S. S. Os condicionantes da competitividade internacional...

TABELA 1 - PRODUÇÃO MUNDIAL DE MAÇÃ, SEGUNDO OS PRINCIPAIS PAÍSES,1999 A 2001 (EM T)

\begin{tabular}{c|c|c|c|c|c}
\hline País & $\mathbf{1 9 9 9}$ & $\mathbf{2 0 0 0}$ & $\mathbf{2 0 0 1}$ & Média & Média (\%) \\
\hline China & 20.809 .846 & 20.437 .065 & 21.507 .000 & 20.917 .970 & 35,1 \\
\hline E.U.A & 4.822 .115 & 4.830 .280 & 4.361 .268 & 2.671 .221 & 7,8 \\
\hline Alemanha & 2.268 .400 & 3.136 .800 & 2.500 .000 & 2.635 .067 & 4,4 \\
\hline Turquia & 2.500 .000 & 2.500 .000 & 2.500 .000 & 2.500 .000 & 4,2 \\
\hline Itália & 2.367 .980 & 2.241 .200 & 2.290 .800 & 2.299 .993 & 3,9 \\
\hline França & 2.165 .800 & 2.156 .900 & 2.032 .000 & 2.118 .233 & 3,6 \\
\hline Irã & 2.137 .037 & 2.000 .000 & 1.900 .000 & 2.012 .346 & 3,4 \\
\hline Polônia & 1.604 .221 & 1.450 .376 & 2.223 .546 & 1.759 .381 & 3,0 \\
\hline Federação Russa & 1.060 .000 & 1.770 .000 & 1.800 .000 & 1.543 .333 & 2,6 \\
\hline İndia & 1.380 .000 & 1.380 .000 & 1.380 .000 & 1.380 .000 & 2,3 \\
\hline Argentina & 1.116 .000 & 833.322 & 1.428 .367 & 1.125 .896 & 1,9 \\
\hline Chile & 1.165 .000 & 908.700 & 1.075 .000 & 1.049 .567 & 1,8 \\
\hline Brasil & 944.812 & 969.085 & 705.515 & 873.137 & 1,5 \\
\hline Espanha & 922.200 & 754.900 & 915.700 & 864.267 & 1,5 \\
\hline Japão & 927.700 & 799.600 & 799.600 & 842.300 & 1,4 \\
\hline Coreia & 650.000 & 650.000 & 650.000 & 650.000 & 1,1 \\
\hline Hungria & 444.508 & 694.586 & 700.000 & 613.031 & 1,0 \\
\hline África do Sul & 618.388 & 565.109 & 565.109 & 582.869 & 1,0 \\
\hline Paquistão & 577.295 & 577.295 & 577.295 & 577.295 & 1,0 \\
\hline Holanda & 575.000 & 575.000 & 575.000 & 575.000 & 1,0 \\
\hline Canadá & 632.525 & 532.218 & 532.218 & 565.654 & 0,9 \\
\hline Subtotal & 49.688 .827 & 49.762 .436 & 51.018 .418 & 50.156 .560 & 84,2 \\
\hline Outros países & 8.573 .349 & 9.680 .878 & 9.946 .382 & 9.400 .203 & 15,8 \\
\hline Total mundial & 58.262 .176 & 59.443 .314 & 60.964 .800 & 59.556 .763 & 100,0 \\
\hline & & & & &
\end{tabular}

FONTE: FAO (2006).

\section{FRAIBURGO E O CULTIVO DA MAÇÃ}

Consta que sua cultura entre os brasileiros sempre esteve limitada a pomares domésticos, não tendo expressão econômica. Até a década de 60 , somente a Região de Valinhos/SP tinha alguns pomares comerciais, cultivados com variedades de baixo valor e que eram vendidas embaladas em caixas de tomate.

A moderna pomicultura brasileira surgiu em 1962, através da SAFRA - Sociedade Agrícola Fraiburgo Ltda, empresa tripartite formada pelos senhores René e Arnoldo Frey - fundadores de Fraiburgo -, Gabriel Evrard, Henri Evrard e Roland Mayer - empresários franco-argelinos - e Albert Mahler - empresário europeu. Este fato foi responsável pela escolha de Fraiburgo como região alvo do presente estudo.
Para melhor conhecer as potencialidades da região, a Safra implantou um grande pomar experimental, onde foram plantadas todas as espécies temperadas com valor comercial, dando ênfase à uva, maçã e frutas de caroço. O pomar experimental abrangia mais de 70 hectares e era dirigido tecnicamente pelo Engenheiro Agrônomo Roger Biau, que trabalhava com os Evrard na Argélia.

Em 1965, dentro do objetivo do Governo Militar, que desejava diminuir a dependência externa do País, o Ministro do Planejamento, Dr. Roberto Campos, solicitou aos Estados Unidos e à França apoio técnico para a implantação da pomicultura em nosso meio. O Governo Americano enviou, em 1965, uma missão técnica for- 
GUIMARÃES, L. M. F. de S. S. Os condicionantes da competitividade internacional...

mada por especialistas do Departamento de Agricultura, que visitaram as Regiões de Valinhos/SP, São Joaquim/ SC, Vacaria, Veranópolis e Pelotas/RS, concluindo que, segundo eles, "o Brasil não tinha condições climáticas para a cultura da macieira em bases comerciais".

Registra-se que em 1966 a França enviou o Viveirista George Delbard e que, com o apoio do Governo Francês, tinha auxiliado na modernização da fruticultura no Marrocos e Irã (Pérsia). Delbard foi levado aos mesmos locais visitados pelos americanos, mas, como tinha fornecido mudas para a Safra em 62/63, incluiu Fraiburgo no roteiro de visitas.

Visitando os pomares experimentais da Safra, o grupo técnico oficial encontrou macieiras das variedades Starkrinson e Golden Spur com uma ótima produção, mostrando a viabilidade econômica da cultura em nosso meio e recomendou a utilização da tecnologia desenvolvida em Fraiburgo para o desenvolvimento da cultura no Brasil.

Por volta de 1969, o Governo Federal Incluiu a macieira na Lei de Incentivos Fiscais Para Reflorestamento, que permitiu o surgimento dos primeiros pomares comerciais na Região de Fraiburgo (Nodarisa e Renar).

Tendo-se iniciado a década de 70, a Secretaria da Agricultura, através de Luiz Gabriel - secretário na época -, teria criado o Programa de Fruticultura de Clima Temperado - Profit, encarregando a Acaresc, sobre a direção do Engenheiro Agrônomo Glauco Olinger, de implantar o referido programa que beneficiava pequenos e médios produtores. A experiência do Profit foi posteriormente levada ao Paraná e Rio Grande do Sul.

Segundo dados divulgados pela prefeitura de Fraiburgo, no que diz respeito ao aspecto turístico, a "Terra da Maçã" têm nos espetáculos da florada das macieiras e na colheita da fruta seus maiores atrativos.

A cidade é responsável por $40 \%$ da produção nacional e $60 \%$ da produção estadual de maçã. O visitante pode passear pelos pomares e colher com as próprias mãos as frutas que desejar ou ir às indústrias e acompanhar a seleção, a classificação e o processo de embalagem da fruta.

Fraiburgo, por sua altitude, apresenta baixas temperaturas durante a maior parte do ano. No inverno, as temperaturas vão até $-10^{\circ} \mathrm{C} \mathrm{e}$, no verão, marcam até $36^{\circ} \mathrm{C}$.

Naturalmente, um dos atrativos turísticos é a gastronomia: pode-se comer uma infinidade de pratos à base de maçã - desidratada, em forma de geleia, torta, compotas, chá. De acordo com a Prefeitura (FRAIBUR$\mathrm{GO}, 2006)$, a cidade foi fundada em 29 de dezembro de 1961, e a ocasião festiva ocorre no final de março ou início de abril (Festa da Maçã).

A maçã é a base da economia de Fraiburgo, que é responsável por $60 \%$ da produção catarinense e $40 \%$ da produção nacional. A cidade também é uma grande produtora de mel - são 15.000 colmeias, que polinizam mais de 7 milhões de macieiras.

A Prefeitura (FRAIBURGO, 2006) informa que 32.500 habitantes são de várias etnias em virtude da colonização Alemã e italiana.

A cidade localiza-se a Meio-Oeste, a $54 \mathrm{~km}$ de Caçador, 87 de Curitibanos, e 380 km Florianópolis. Fraiburgo está $41 \mathrm{~km}$ ao norte da BR-470, pela SC-456 e SC-453. O acesso fica $40 \mathrm{~km}$ depois de Curitibanos, para quem vem do litoral, ou $27 \mathrm{~km}$ depois de Campos Novos, para quem vem do oeste. Para quem vem do norte, Fraiburgo está a $54 \mathrm{~km}$ de Caçador, via SC-303/SC-453.

A altitude é $1.100 \mathrm{~m}$ acima do nível do mar, ao passo que as cidades mais próximas são Videira, Joaçaba, Pinheiro Preto, Curitibanos, Treze Tílias, Tangará, Caçador, Campos Novos.

De acordo com a Prefeitura Municipal de Fraiburgo (2006), a cidade foi fundada pela família Frey, originária da Alsácia, que chegou à região em 1919 atraída pelo ciclo da madeira e instalou ali uma serraria. A família abriu as primeiras ruas e construiu uma barragem - que deu origem a um lago artificial, o Lago das Araucárias, verdadeiro cartão-postal da cidade. Este espírito desbravador trouxe rápido desenvolvimento à região, que se tornou distrito em 1949 e cidade em 1961, desmembrando-se de Videira e de Curitibanos. Com a diminuição das matas devido à exploração da madeira, os colonizadores começam a buscar alternativas econômicas. Além de plantar uva para fabricar vinho, os Frey produzem mudas frutíferas europeias e dão início à transformação de Fraiburgo na Terra da Maçã - a fruta que melhor se adaptou à região e ao clima. De 1912 a 1916, o município vivenciou a sangrenta Guerra do Contestado.

A maior parte dessa região era primitivamente coberta por imensas florestas nativas, onde, além da imbúia, do cedro, da canela, da erva mate, predominavam os majestosos pinheiros, tão típicos das paisagens sulinas do Brasil.

A Prefeitura (FRAIBURGO, 2006) documenta também que no planalto Catarinense, as primeiras fazendas surgiram por volta da metade do século XIX, depois da Revolução Farroupilha (1835-1845), Guerra do Paraguai (1864-1870), e mais tarde da Revolução Federalista (1893-1895), o planalto começou a ser mais intensamente povoado por fugitivos e remanescentes daquelas lutas, vindos principalmente, a partir de Lages e do Rio Grande do Sul. Apareceram, a partir daí, gran- 
des fazendas, por posse de terras devolutas e compra de antigas posses, com peões, zeladores, agregados, arrendatários, meeiros e posseiros. Duas destas gran- des glebas de terra viriam a ter particular importância no surgimento do futuro Município de Fraiburgo: as fazendas "Liberata" e "Butiá Verde".

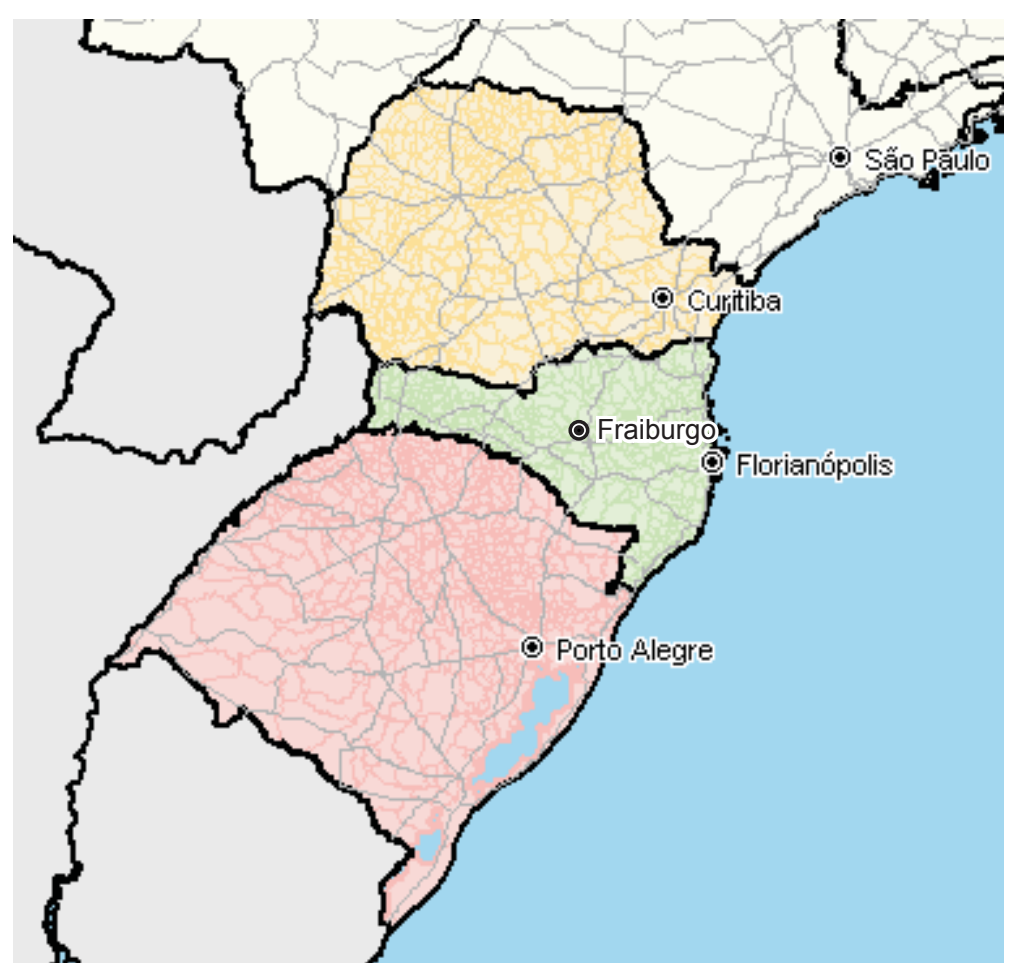

FIGURA 1 - PERFIL DO MUNICÍPIO DE FRAIBURGO

Fonte : Atlas do Desenvolvimento Humano no Brasil

Consta nos registros da Prefeitura que as primeiras famílias que habitavam a região do "Campo da Dúvida" teriam sido Naper ou Anaper (por volta de 1880). As famílias pioneiras ligadas à fazenda Liberata foram as famílias: Marcondes, Gomes, Damaceno, Palhano, Weber.

Com o passar dos anos, as terras antes pertencentes aos Ramos e a outros antigos proprietários da região, foram sendo adquiridas pelos Frey, tornando-os praticamente senhores de Butiá Verde. Este fato iria ter grande influência sobre o futuro desenvolvimento da cidade e da região.
Segundo informação da Prefeitura Municial de Fraiburgo (FRAIBURGO, 2006), é fácil ver como Fraiburgo teve seu auge no setor primário até a década de 50/60, a indústria extrativa de madeira, pioneira e geradora do município, ainda é a propulsora da economia, mas foi a fruticultura da maçã que tornou-se reconhecida nacional e internacionalmente.

É justamente neste período que nascem os primeiros plantios de macieiras, nos meados da década, onde o experimento de variedades está direcionado à aclimação, e nos estudos do uso racional do solo, nas matrizes, porta-enxertos e na importação das primeiras 10.000 mudas de macieiras da França. 


\section{ENTREVISTAS COM OS GESTORES}

No dia 25 de Julho de 2006, foi visitada a empresa Fischer Fraiburgo Agrícola, e foi entrevistado Sílvio José Gmach, gerente industrial. Ele mencionou que a Fischer é uma empresa de grande porte, tendo a instalação mais moderna no mundo onde tudo é automatizado. As máquinas são francesas, alemãs, Inglesas, americanas e italianas e que no mundo existem de 5 a 6 fábricas dessas máquinas. Citou que o Brasil não tem interesse em produzir máquinas de alta tecnologia, pois o projeto é muito grande e muito oneroso. Possui uma logística diferenciada e consequentemente abastece os grandes supermercados (transnacionais). $O$ fator de vantagem competitiva entre janeiro e fevereiro para a maçã é que de dia tem altas temperaturas e quando a noite esfria, nesse processo climático a maçã fica mais vermelha.

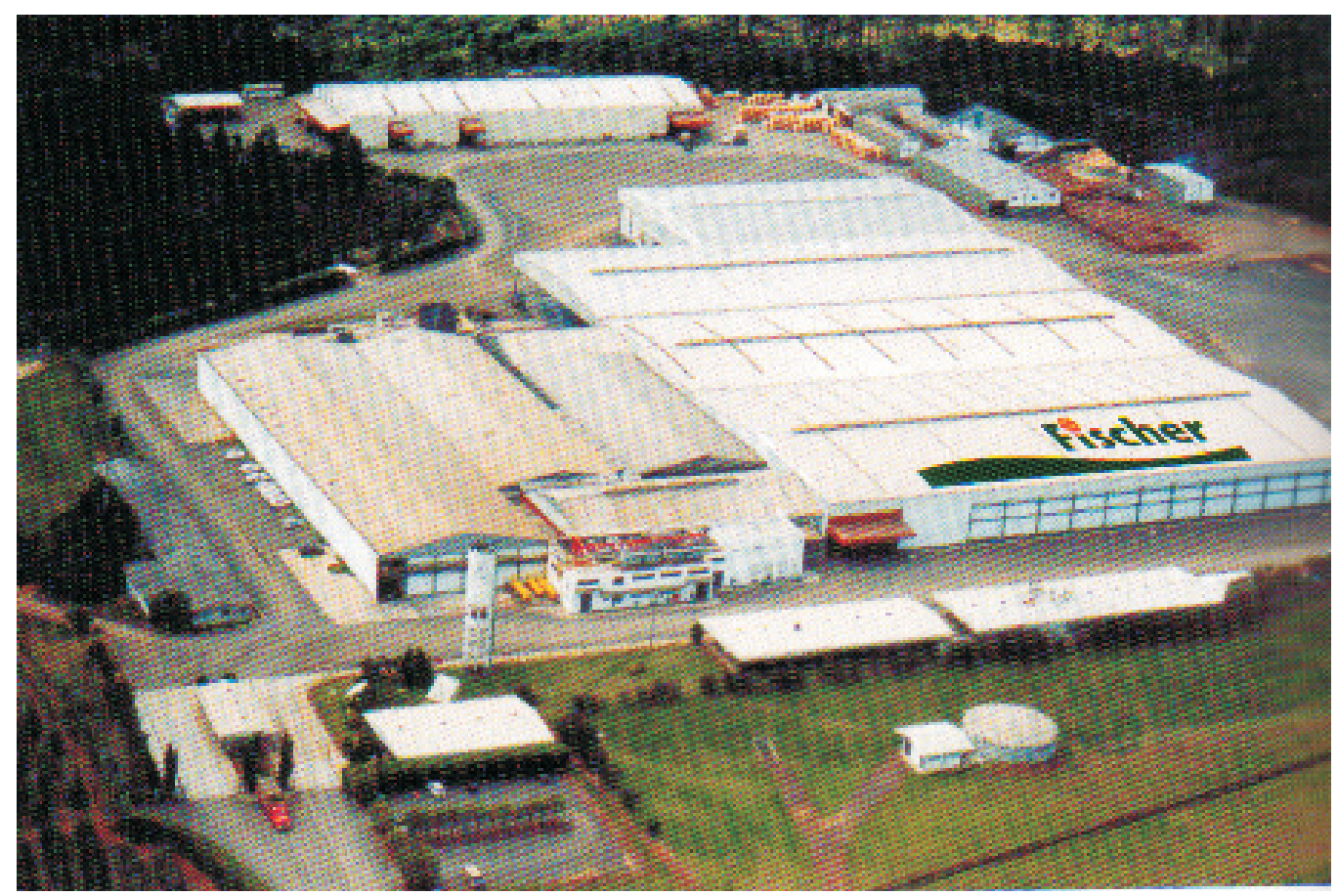

FIGURA 2 - VISTA AÉREA DA FISCHER FRAIBURGO AGRÍCOLA

No dia seguinte, 26 de julho, foi realizada a entrevista na ABMP - Associação Brasileira de Pomicultura da Maçã, com Moisés L. de Albuquerque, gerente executivo. Moisés relatou que a Associação tem um trabalho de representação política do setor e que congrega todos os principais polos de produção do Brasil, sendo o principal, a cidade de Fraiburgo, depois Vacaria RS, São Joaquim SC. e Palmas PR. Mencionou que a representação política busca as melhores condições em todo o estado em termos de tributações, financiamento, pesquisa e desenvolvimento técnico da pomicultura. A Associação tem toda concentração de estatística, projeto de biotecnologia, acompanhamento econômico e marketing, citou como exemplo a maçã "Turma da Mônica", cujos commodities chegam aos consumidores sem marca no mercado externo. Com relação às ameaças na pomicultura, citou como exemplo o trabalho de erradicação de uma praga importantíssima, a principal praga da maçã de nível mundial. Nesta ocasião são feitos esforços dos produtores junto com o governo afim de arrecadar fundos para restabelecer e erradicar a praga no Brasil que ainda não chegou aos pomares comerciais e sim em algumas regiões urbanas. Citou-se que o país que mais importa a maçã de Fraiburgo é a Holanda, chegando lá é distribuída para outros países, porque a Holanda é o maior importador de frutas do mundo, distribuindo para a Europa e outros países. A Holanda no passado chegou a comprar $90 \%$ da maçã, hoje apenas 47 a $48 \%$. Atualmente as empresas conseguiram venda direta, aumentou a venda na Escandinávia, mercado Inglês, Alemanha, Holanda, França. 


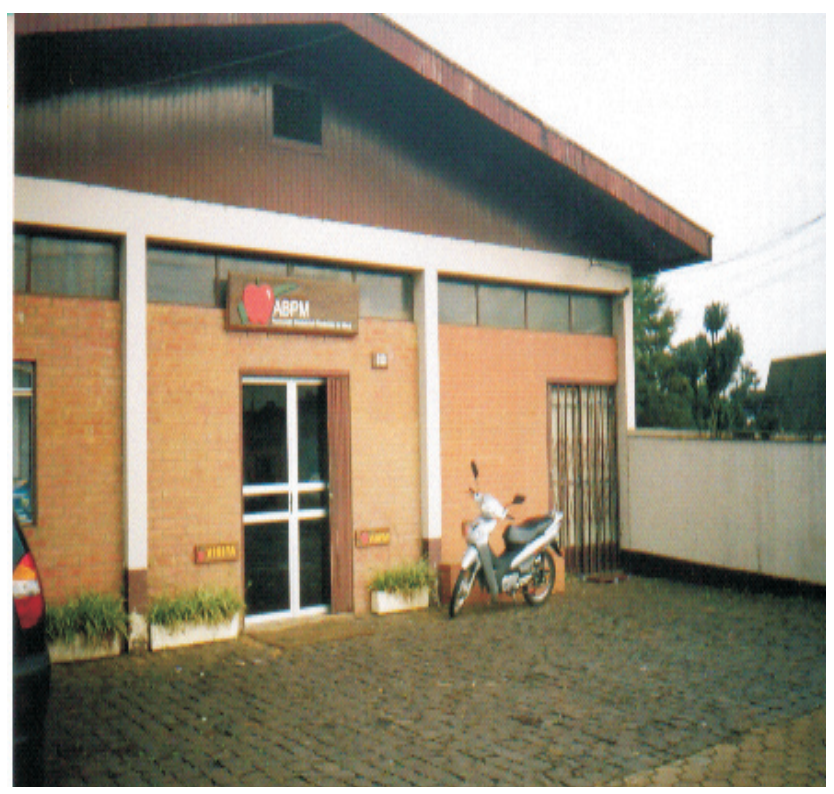

FIGURA 3 - FACHADA DA ASSOCIAÇÃO BRASILEIRA DE POMICULTURA DA MAÇÃ EM FRAIBURGO

Em seguida foi visitada a Pomagri Frutas Ltda., onde foi entrevistado Edimarco Debona, engenheiro horticultor, gerente industrial. Debona relatou que em 1989 aconteceu a primeira exportação e que em 90 houve a expansão. Afirmou que durante os anos de 2005/2006 o desempenho não foi muito bom. Exportaram para a Inglaterra (país onde há maçã na merenda escolar duas vezes por semana) e são fornecedores para duas empresas. Sendo assim, existe fiscalização inglesa nas empresas. A Pomagri Frutas possui 70 ha de macieira e terceiriza a prestação de serviços. Os consumidores internos, no nordeste do Brasil, consomem a fruta pequena e no sul do Brasil consomem a grande. Conforme o clima, a macieira desenvolve mais ou não.

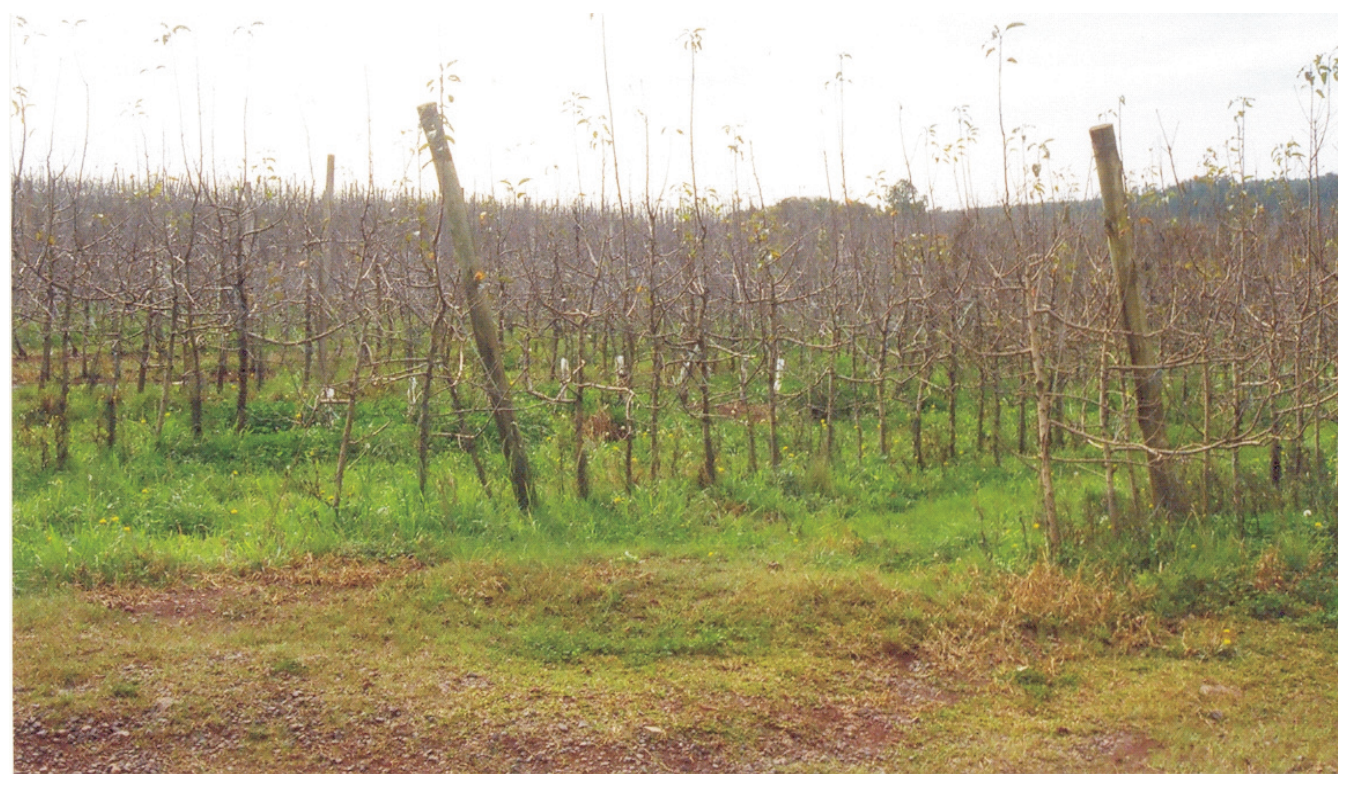

FIGURA 4 - FAZENDA DE MAÇÃ DA POMAGRI 
Na sequência foi entrevistado o Diretor Presidente da Renar Maçãs, Roberto Frey. Ele afirmou que numa primeira etapa o caminhão traz as maçãs para serem analisadas e terem controle de qualidade, semelhante ao raio $\mathrm{X}$ geral (calibre) por campo. Outra etapa é a logística. Quando as frutas chegam recebem um banho de água gelada, pois são provenientes das fazendas com temperatura $25^{\circ}$. Levam jato de água gelada por 20 min a 30 min para o metabolismo da fruta baixar e em seguida são armazenadas nas câmaras frigoríficas. A empresa recebe fruta de outros pomares, processo que é muito bem controlado. Controla-se a atmosfera, a temperatura, umidade, gás carbônico, oxigênio. A exportação rápida da maçã é recente. Por volta de 86/87, começou a crescer mais que a demanda, mais que o crescimento do país. O volume da colheita de janeiro a maio/2005 foi de 1.000 .000 toneladas, os outros 500 mil toneladas no período de safra. Foi citado que na verdade o governo não ajuda muito em nenhum aspecto. Toda agricultura brasileira não tem custeio agrícola, qualquer custeio é de valor irrisório. Hoje todo mundo tem que trabalhar basicamente com recursos próprios, os recursos bancários têm taxas astronômicas, o governo simplesmente taxa cada vez mais as empresas e os setores. Para regulamentar as exportações seria necessário mais presença do governo, assinando tratados, contratos com outros países e isso o governo não tem feito, não de forma satisfatória para os brasileiros.

Com relação às vantagens e desvantagens competitivas dos produtores de Fraiburgo, pediu-se que qualificassem os principais fatores de produção como favoráveis ou desfavoráveis.

Revelou-se que a mão de obra é qualificada, pois, sendo a cidade da maçã eles já trabalharam ou trabaIham no setor e cada vez mais aprimoram a técnica. $O$ solo e o clima também são satisfatórios, desde que não haja uma seca como a que estamos atravessando.

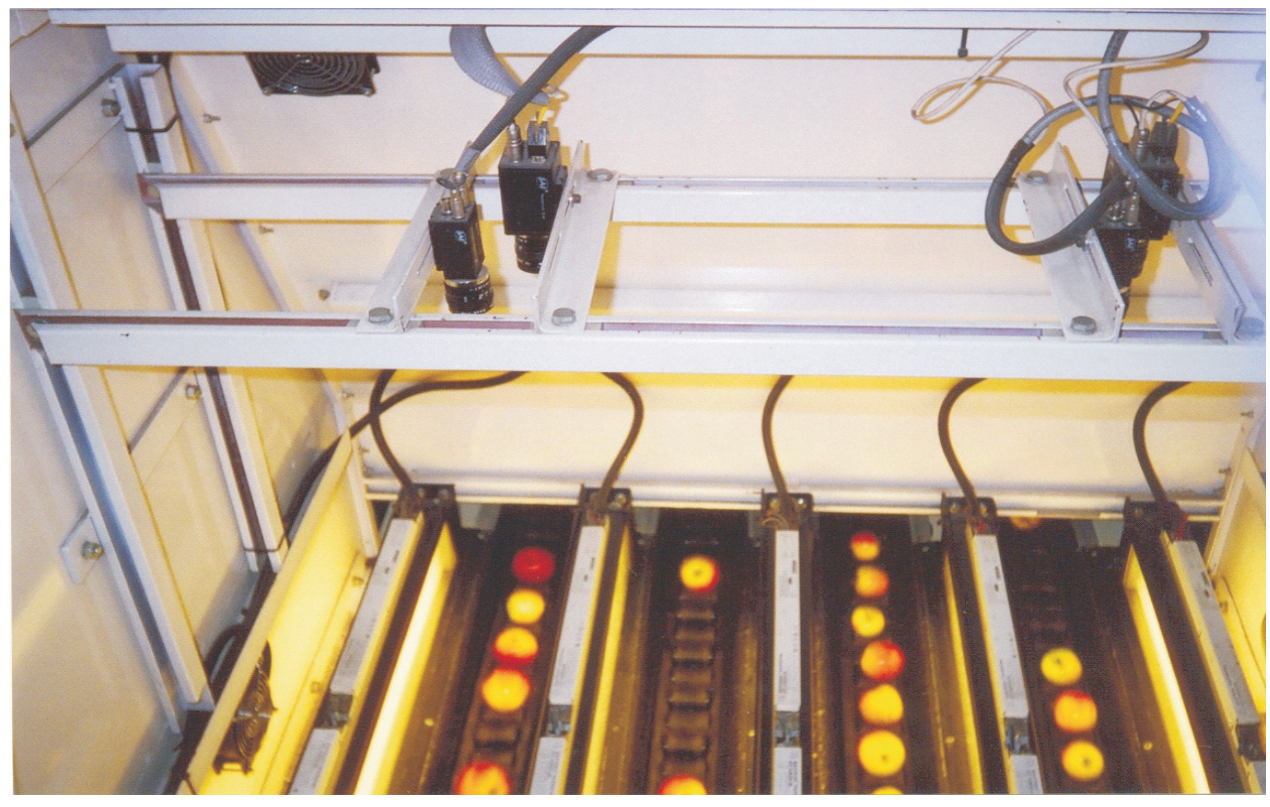

FIGURA 5 - ALTA TECNOLOGIA DA RENAR MAÇÃS

Foi entrevistada também a Agrícola Fraiburgo S/A, representada por Francisco Homsi, Trading Manager. A produção nacional é de 5\%, 3.500 toneladas, têm pomar próprio. Aconteceram grandes transformações em 2002. Estava concentrada em Fraiburgo hoje dá mais expansão em outros municípios; Ex: São Joaquim, Água Doce, próximo à divisa ao Paraná e também em Vacaria RS. O custo de manutenção é bastante elevado e não há qualquer incentivo do governo, e quando há é muito irrisório, porque o custo por hectare da maçã é muito maior comparado às outras culturas. A questão do mercado é muito complexa e varia. O mercado divide-se em duas parcelas distintas: a parcela do mediterrâneo, onde a busca pela fruta é mais graúda, são consumidores tradicionais. Ex: Sul da Itália, Sul da França e principalmente Portugal. Depois vem a Europa do Norte com duas realidades distintas: a Inglaterra à parte, mercado dominado por supermercados onde se usa a fruta na merenda escolar (vários produtores participam desse programa), e a realidade da Escandinávia, que 
GUIMARÃES, L. M. F. de S. S. Os condicionantes da competitividade internacional...

é um mercado muito forte em briga de preço.

Finalmente, foi ouvido o Secretário do Desenvolvimento Econômico do Município de Fraiburgo, Ademir Pedro Perin. Verificou-se que eles não têm opinião única formada sobre as vantagens competitivas, mas a maçã é a segunda economia do Município; a primeira é o papel (fábrica de celulose movimento econômico de valores), e a terceira é o transporte. A maçã é que mais emprega e que dá mais movimento à cidade. Algumas ações têm sido tomadas para o desenvolvimento do turismo local que até então era muito isolado. O poder público não acompanhava os empreendedores no setor turístico que estavam fazendo investimento.

O surgimento da Lei 5.106, criada no ano de 1966, pelo presidente Castello Branco, devido à alta importação de frutas, interessava para fruticultura e para pomicultura. Foi através do governo Federal que pomicultura ganhou um enorme impulso no município de Fraiburgo.

O que ficou claro na pesquisa é que a logística da maçã é o foco principal do fator competitividade. Se bem armazenada e bem transportada, é bem aceita pelos mercados. A tecnologia é um fator competitivo, pois percebeu-se que os empresários melhor supridos em termos de maquinário, seja a empresa de pequeno, médio ou grande porte, têm maior poder de conservação e armazenamento e consequentemente, boa distribuição.

As questões relacionadas ao meio ambiente estão de acordo com os requisitos legais do município e normas internacionais, devido à fiscalização rigorosa.

O turismo é um chamariz e uma propaganda positiva para a localidade.

Conforme se percebeu na pesquisa feita, a ênfase que vem sendo dada ao tema da competitividade das localizações resulta de um conjunto de fenômenos de natureza multidisciplinar, envolvendo os aspectos macroeconômicos, microeconômicos, sociais, políticos e institucionais.

Percebeu-se que a "globalização e o movimento de capitais diminuem o poder das autoridades nacionais em controlar a macroeconomia", segundo PORTER (1993) pois variáveis como câmbio, juros e balanço de pagamentos dependem fortemente da evolução do cenário econômico e político mundial. Foi citado inclusive, por um empresário, que após o episódio de 11 de setembro veio uma lei anti-terrorista americana ordenando algumas medidas a serem tomadas em alguns setores da fábrica.

A palavra chave da globalização é eficiência. Não mais apenas como meio de reduzir o trabalho humano ou de aumentar os lucros na atividade empresarial, mas, além disso, produzir bens e serviços de melhor qualidade, mais rapidamente e em maior quantidade. Nesse contexto, cada entidade, seja ela pública ou privada, local, regional, nacional ou multinacional, deve estabelecer definitivamente a sua vocação para satisfazer, da melhor maneira possível e com os menores custos, as demandas tradicionais e emergentes das sociedades de todas as latitudes.

Em nível político, crescem as demandas por participação de segmentos representativos da sociedade. No campo organizacional e institucional, ocorre a mudança do papel do Estado, a inversão da pirâmide hierárquica no sentido da descentralização e da transferência de poder para entes da sociedade civil.

A interiorização do desenvolvimento e o fortalecimento da competitividade das localizações brasileiras nas atividades relacionadas à agricultura dependem de avanços tecnológicos na agricultura e a realização de estudos ambientais complexos no setor alimentício e controle de pragas.

A realização do trabalho indica a execução de planos integrados de desenvolvimento - não apenas no ramo do agronegócio - é a chave para a criação e distribuição de riquezas do país.

\section{CONCLUSÃO}

Primeiramente, cabem algumas considerações sobre a competitividade e seus obstáculos. A competitividade, neste trabalho entendida como promoção de maior eficiência e produtividade, pode ser observada através de dois grupos de indicadores: a medida de eficiência na utilização de recursos, a produtividade de mão de obra, retorno de capital, indicadores de crescimento e nível de atividade e o investimento em tecnologia. Concluiu-se que a competitividade poderia

ser definida como a capacidade de uma indústria (ou empresa) produzir mercadorias com padrões de qualidade específicos, requeridos por mercados determinados, utilizando recursos em níveis iguais ou inferiores aos que prevalecem em indústrias semelhantes no resto do mundo, durante um certo período de tempo.

Nesse sentido, fatores como marketing, serviços junto a clientes e canais de comercialização também podem influir na competitividade (caracterizando re- 
GUIMARÃES, L. M. F. de S. S. Os condicionantes da competitividade internacional...

quisitos para penetração em mercados específicos), mesmo quando definida de modo independente do desempenho comercial.

No que diz respeito à pomicultura em geral, concluiu-se que o milênio iniciou-se sob a marca da redução no ritmo das atividades econômicas em todo o mundo. Os ganhos de produtividade da agricultura, que proporcionaram aumentos de produção com redução de preços, nas últimas décadas do século $X X$, esbarram em crescimento do desemprego e redução do poder de compra dos consumidores. No caso específico da maçã brasileira, sua vigorosa expansão encontra, agora, poderosas limitações. Inquietações e buscas de saídas são manifestadas pelos técnicos e empresários do setor.

O aumento da produção de maçã é preocupante para o setor, que enfrenta um panorama de excesso de oferta nos mercados nacional e mundial. Os desafios do mercado para os produtores brasileiros ficaram mais intensos a partir do momento em que a superoferta resultou da produção nacional. Quando competia apenas com o produto importado, as providências eram menos complicadas.

As fortes chuvas ocorridas em 2000 e 2001, que provocaram forte redução na oferta da maçã, retardaram os efeitos da crise. Mas, recuperado todo o potencial produtivo da pomicultura nacional, o problema da oferta superior à demanda se apresenta em toda sua magnitude.

Se, por um lado, a oferta de maçã de tipo inferior deprecia o mercado, por outro, milhões de brasileiros de baixa renda têm um grande potencial de consumo da fruta.

Campanhas de distribuição de maçã de tipo inferior nas periferias das metrópoles brasileiras, a exemplo do que já ocorreu nos varejões de São Paulo, na década de 80 , poderiam colaborar para garantir melhor remuneração aos produtores.

\section{REFERÊNCIAS}

ANUÁRIO DAAGRICULTURA BRASILEIRA. Agrianual 2002. São Paulo: FNP \& Consultoria, 2001. p. 370-380.

ARAUJO JUNIOR, J. I. Mudanças tecnológicas e competitividade das exportações brasileiras de manufaturados. In: ENCONTRO NACIONAL DE ECONOMIA, 10., 1982. Rio de Janeiro: Anpec, 1982. v. 2.

ASSOCIAÇÃO BRASILEIRA DE PRODUTORES DE MAÇÃ (ABPM). Informações estatísticas. Disponível em: <http://www. abpm.org.br>. Acesso em: 20/6/2006.

Cultura brasileira da maçã. Disponível em: <http://www.todafruta.com.br/todafruta/mostra_conteudo. asp?conteudo=1470 > . Acesso em: 20/06/2006.

. Comércio exterior e mudança estrutural na economia brasileira: 1970-83. Disponível em: <www.nethistoria.com> Acesso em: 20/05/2006. Texto para Discussão. n. 56, IEI/ UFRJ, 1984.

BIAU, Roger Marie Gilbert. Depoimento sobre Fraiburgo. In: BRANDT, Marlon. "Frey"burgo: acumulação de capital no setor macieiro e continuidade política no município de Fraiburgo na década de 1960. Trabalho de Conclusão de Curso (Bacharelado em História) - Centro de Educação, Universidade do Estado de Santa Catarina, Florianópolis, 2004.

BRANDT, Marlon. "Frey"burgo: acumulação de capital no setor macieiro e continuidade política no município de Fraiburgo na década de 1960. 2004. Trabalho de Conclusão de Curso (Bacharelado em História) - Centro de Educação, Universidade do Estado de Santa Catarina, Florianópolis, 2004.
. A criação da Sociedade Agrícola Fraiburgo (Safra) e o início da pomicultura em Fraiburgo - SC, na Década de 1960. Revista Discente Expressões Geográficas. Florianópolis-SC, n. 1, p. 27-41, jun. 2005.

DINIZ FILHO, L. L; VICENTINI, Yara. Teorias espaciais contemporâneas - o conceito de competitividade sistêmica e o paradigma da sustentabilidade ambiental. In: MENDONÇA, Francisco (Org). Impactos socioambientais urbanos. Curitiba: UFPR, 2004.

DOSI, G., Absolute and comparative advantages in international trade: some emprirical evidence, mimeo, 1984.

EVRARD, Henri. Henri Evrard: Depoimento, novembro 2003, Fraiburgo. Entrevistador: Marlon Brandt. In: BRANDT, Marlon. A criação da Sociedade Agrícola Fraiburgo (Safra) e o início da pomicultura em Fraiburgo - SC, na década de 1960. Revista Discente Expressões Geográficas. Florianópolis-SC, n. 1, p. 27-41, jun. 2005.

EVRARD, Paul Gabriel. Paul Gabriel Evrard: Depoimento sobre Fraiburgo: Entrevistadora: Andréia Melo. Acervo Rádio Fraiburgo. In: BRANDT, Marlon. "Frey"burgo: acumulação de capital no setor macieiro e continuidade política no município de Fraiburgo na década de 1960. Trabalho de Conclusão de Curso (Bacharelado em História) - Centro de Educação, Universidade do Estado de Santa Catarina, Florianópolis, 2004.

FAJNZYLBER, F. Sistema industrial e exportação de manufacturados: análise da experiência brasileira. Rio de Janeiro: IPEA/INPES, 1971. (Relatório de Pesquisa, n. 7) Brasil. Instituto de Planejamento Econômico e Social. Instituto de Pesquisas, 1971. 
GUIMARÃES, L. M. F. de S. S. Os condicionantes da competitividade internacional...

La transformación productiva con equidad y la sustentabilidad ambiental. Industrialización y Desarrollo Tecnológico, n. 12, p. 7-26, abr. 1992.

FAO. Faostat. Disponível em: <http://apps.fao.org/page/colle ctions?subset=agriculture $>$. Acesso em: 20/06/2006.

FERRAZ, J. C. A heterogeneidade tecnológica da indústria brasileira; perspectivas e implicações para política. Texto para Discussão. n. 185, IE/UFRJ, Rio de Janeiro, 1989.

FRAIBURGO. Disponível em: <www.fraiburgo.sc.gov.br>. Acesso em: 20/06/2006.

FREY, Willy. Reflorestar é a solução. Curitiba: Sépia Editora, 2003.

Fraiburgo, berço da maçã brasileira. 4. ed. Curitiba: Sépia Editora, 2004.

GONÇALVES, J. S. et al. Produção, mercado e inserção internacional da maçã brasileira. Agricultura em São Paulo, São Paulo, v. 43, t. 1, p. 95-136, 1996.

IBGE. Orçamento Familiar. Disponível em: <http://www.sidra. ibge.gov.br/bda>. Acesso em: 20/06/2006.

KOTLER, P. Administração de marketing: análise, planejamento, implementação e controle. São Paulo: Atlas, 1993.

KOVALESKI, A. Embrapa, um marco na fruticultura. Disponível em: <http://www.mko.com.br/jornalagapomi/mat_114_03. htm>. Acesso em: 20/06/2006.

MENDONÇA, Francisco (Org). Impactos socioambientais urbanos. Curitiba: UFPR, 2004.

MINISTÉRIO DE DESENVOLVIMENTO, INDÚSTRIA E COMÉRCIO EXTERIOR. SECEX. Balança Comercial Brasileira. Rio de Janeiro, 1999-2002.

NELSON, R. R. Research on productivity growth and productivity differences: dead ends and new departures: Journal of Economic Literature, Pittsburg, v. 19, n. 3, p. 10291064, sept. 1981.
OLIVEIRA, Eden G.F. Tecnologia Industrial, mimeo, Rio de Janeiro: FGV, 1988.

PENALVER, M.; BOLTE, E.; DAHLMAN, C.; TYLER, W. Política industrial e exportação de manufaturas do Brasil. Rio de Janeiro: Banco Mundial e FGV, 1983.

PEREZ, L. H; GONÇALVES, J. S; SOUZA, S. A. M. Substituição da maçã importada pela nacional: alterações na sazonalidade de preços e quantidades. Informações Econômicas, São Paulo, v. 28, n. 6, p. 7-24, jun. 1998.

PORTER, Michael E. A vantagem competitiva das nações. Rio de Janeiro: Campus, 1993.

PORTUGAL, Alberto Duque. O desenvolvimento da Biotecnologia Agropecuária no Brasil. Revista de Política Agrícola. Brasília: CONAB, v. 9. n. 3. p. 16-38, set. 2000.

SANTA CATARINA. Governador Ivo Silveira. Projeto de fruticultura de clima temperado. Florianópolis, 1970.

SCHIMIDT, Wilson. O setor macieiro em Santa Catarina: formação e consolidação de um complexo agroindustrial. $258 \mathrm{f}$. Dissertação (Mestrado em Desenvolvimento Agrário) - Instituto de Ciências Humanas e Sociais, Universidade Federal Rural do Rio de Janeiro, Itaguaí, Rio de Janeiro, 1990.

SCHMITZ, Sérgio. Planejamento estadual: a experiência do Plameg. Florianópolis: UFSC, 1985.

SILVA, Mozart Foschete. Relações Econômicas Internacionais. São Paulo: Aduaneira, 1999.

STINCHCOMBE, Arthur L. Classes sociais e meio rural. In: SZMRECSÁNYI, Tamás; SZMRECSÁNYI, Tamás. Pequena história da agricultura no Brasil. São Paulo: Contexto, 1990.

SUZIGAN, Wilson. Reestruturação industrial e competitividade nos países avançados e nos NIC's asiáticos: lições para o Brasil In: SUZIGAN, W. et al. Reestruturação industrial e competitividade internacional. São Paulo: Fundação SEADE, 1989. 